\title{
Effect of Terpenes on the Skin Permeation of Lomerizine Dihydrochloride
}

Takayuki Furuishi $^{a}$, Yukiko Kato ${ }^{b}$, Toshiro Fukami ${ }^{b}$, Toyofumi Suzuki ${ }^{b}$, Tomohiro Endo ${ }^{a}$ Hiromasa Nagase $^{a}$, Haruhisa Ueda $^{a}$, Kazuo Tomono ${ }^{b}$

a Department of Physical Chemistry, Hoshi University, 2-4-41 Ebara, Shinagawa-ku, Tokyo, Japan. ${ }^{\mathrm{b}}$ Laboratory of Pharmaceutics, School of Pharmacy, Nihon University, 7-7-1 Narashinodai, F unabashi-shi, Chiba, Japan

Received July 29, 2013; Revised, September 7, 2013; Accepted, September 12, 2013; Published, September 12, 2013.

\begin{abstract}
Purpose. Lomerizine dihydrochloride (LOM) is a $\mathrm{Ca}^{2+}$ channel blocker used as an antimigraine drug, which is currently administered orally in Japan. We therefore investigated the effect of terpenes in propylene glycol (PG) solvent on the percutaneous absorption of LOM by hairless mouse skin. Methods. Attenuated total reflection-Fourier transform infrared spectroscopy (ATR-FTIR), confocal laser scanning microscopy (CLSM), and small angle X-ray scattering (SAXS) were carried out to analyze the effects of terpene enhancers on the biophysical properties of the stratum corneum (SC) of the skin. Results. Of the terpenes tested, the highest permeation rate of $\operatorname{LOM}\left(28.8 \mu \mathrm{g} / \mathrm{cm}^{2} / \mathrm{h}\right)$ was observed with 1,8 -cineole, while nerolidol conferred the lowest enhancement of LOM flux $\left(14.2 \mu \mathrm{g} / \mathrm{cm}^{2} / \mathrm{h}\right)$. ATR-FTIR studies revealed that terpenes/PG induced higher $\mathrm{CH}_{2}$ stretching frequencies of $\mathrm{SC}$ lipids than $\mathrm{PG}$ alone. The extent of penetration of the lipophilic fluorescence probes Nile Red and DiI was measured by CLSM in in vitro skin permeation studies, using either PG or terpenes/PG as skin permeation enhancers. With PG alone, both fluorescence dyes were undetectable in the skin. In contrast, when co-administered with terpenes/PG, both probes were distributed into the intercellular space between corneocytes and detected in the deeper layers of the skin. SAXS measurements showed that in SC treated with a combination of 1,8-cineole and PG, the scattering peak of the $\mathrm{SC}$ was broad and very weak in intensity compared to untreated SC, whereas pretreatment with PG alone did not alter the peak profile. Conclusion. A combination of terpenes and PG enhance the skin permeation of LOM. Our findings suggest that the mechanism for this effect involves the ability of terpenes to increase the fluidity of SC lipids, thus enhancing the distribution of LOM into the intercellular region of the SC.
\end{abstract}

This article is open to POST-PUBLICATION REVIEW. Registered readers (see "For Readers") may comment by clicking on ABSTRACT on the issue's contents page.

\section{INTRODUCTION}

Migraine is a primary headache disorder characterized by recurring attacks of throbbing (often unilateral) headache, photophobia, phonophobia, nausea, and other symptoms. The headache may be preceded by transient focal neurologic symptoms known as aura. The prevalence of migraine peaks in midlife, and in the United States alone more than 28 million people, approximately $18 \%$ and $6 \%$ of the female and male populations, respectively, have experienced migraine (1). Sakai and Igarashi performed a nationwide survey of Japan by telephone interview and reported a migraine prevalence of $8.4 \%$ (2). The high prevalence of migraine is concerning because in a large American cohort migraine was associated with increased risk of subsequent major cardiovascular disease, which was driven by increased risk of myocardial infarction (3).
Lomerizine dihydrochloride (1-[Bis(4fluorophenyl)methyl] - 4 - (2,3,4 trimethoxybenzyl) piperazine dihydrochloride, LOM, Figure 1) is a synthetic $\mathrm{Ca}^{2+}$ channel blocker developed as an antimigraine drug (4), which is currently administered in an oral dosage form (Terranas ${ }^{\circledR}$ Tablets $5 \mathrm{mg}$ and Migsis ${ }^{\circledR}$ Tablets $5 \mathrm{mg}$ ) in Japan. The oral LOM formulation is usually administered twice a day, and treatment is usually continued for several months. Imai et al. reported that LOM is effective for long-term prophylaxis against frequent migraine, and that it may be even more effective in younger patients (5). Hence, there may be a clinical need for LOM to be made available as a long-acting formulation for migraine.

Corresponding Author: Takayuki Furuishi, Ph.D.; Department of Physical Chemistry, Hoshi University, 2-4-41 Ebara, Shinagawa-ku, Tokyo, Japan; E-mail: t-furuishi@hoshi.ac.jp 


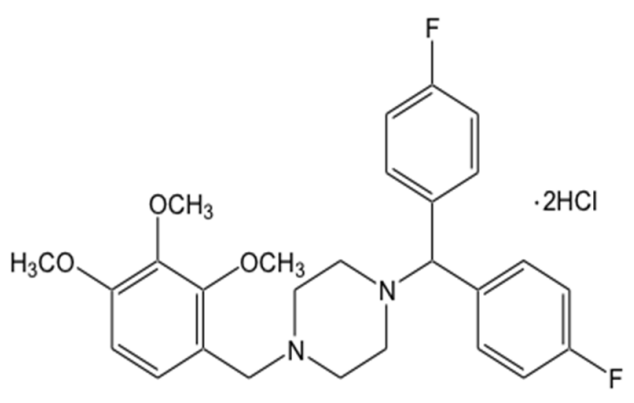

Figure 1. Chemical structure of lomerizine dihydrochloride (LOM).

Transdermal drug delivery (TDD), the delivery of drugs across the skin, is gaining wide acceptance among patients (6). Transdermal drug delivery systems (TDDS) offer a number of advantages over conventional drug administration methods: avoidance of the hepatic first-pass metabolism, improving bioavailability, longer duration of action, reducing side effects and improving patient compliance $(7,8)$.

However, the stratum corneum (SC), the outermost layer of the skin, is the principal limitation to percutaneous delivery. The (SC) is composed of keratin-rich cells embedded in multiple lipid bilayers, which are mainly comprised of ceramides, cholesterol, and free fatty acids $(9,10)$. It is widely accepted that the intercellular lipid domain is the main pathway for penetration of most drugs through the SC (11). Both physical methods (SC stripping, iontophoresis, phonophoresis and microneedle) $(8$, 12) and chemical methods (use of lipophilic analogues and skin permeation enhancers) are used to promote the delivery of drugs across the skin. Of these methods, the most widely implemented approach to increase percutaneous absorption is the use of skin permeation enhancers, which ideally cause a temporary, reversible reduction in the barrier function of the SC in order to facilitate safe and effective drug delivery through the skin (13). However, there are cases where enhancement of skin permeation cannot be obtained using chemical enhancers.

Often, a parabolic dependence is found between skin permeation and the octanol-water partition coefficient (P) of the drug, with an optimum value of $\log \mathrm{P} \approx 2(14,15)$. At low $\log \mathrm{P}$, (i.e., hydrophilic molecules), the permeability is low since partitioning into the skin lipids is low. In this case, drug permeation can be improved by increasing the thermodynamic activity of the drug in the transdermal formulation (16), by the use of a permeation enhancer, or by physical enhancement strategies (e.g., iontophoresis, phonophoresis or microneedle) $(8,12)$. Surprisingly, at high $\log \mathrm{P}$ values, (i.e., highly lipophilic molecules), permeability is also low. This is probably due to accumulation of lipophilic drugs in the SC because of low aqueous solubility. Although there are many examples given in the literature with respect to permeation enhancement of hydrophilic and moderately lipophilic drugs (14), to date there are few examples of permeation enhancement of highly lipophilic drugs. The percutaneous absorption of LOM is expected to be low, due to its highly lipophilic nature $(\log P=4.8)$. Indeed, to the best knowledge of the authors, no research has yet been carried out with respect to enhancing the skin permeation of LOM with permeation enhancers.

Terpenes are a safe and effective class of skin permeation enhancer, derived from plant essential oils. The US Food and Drug Administration classify them as "Generally Regarded as Safe" (GRAS) (17). It has been reported that terpenes have good toxicological profiles and high percutaneous enhancement abilities $(18,19)$. Terpenes, in combination with co-solvents (e.g., ethanol or propylene glycol (PG)) have been investigated as skin permeation enhancers for both lipophilic (e.g., haloperidol, $\log \mathrm{P}=3.36$ ) (20) and hydrophilic drugs (e.g., 5-fluorouracil, -0.89) (21). However, there is a little information on the ability of terpenes to enhance the transdermal delivery of highly lipophilic drugs $(>\log \mathrm{P}=4)(22)$.

In this paper, we proposed to improve the percutaneous absorption of LOM using various terpenes in PG solution. PG has been widely employed to enhance the transdermal flux of drugs (23) and has been used as a co-solvent for many enhancers $(24,25)$. The skin permeation of LOM through hairless mouse skin as a model membrane was measured using Franz diffusion cells, in order to identify terpenes appropriate for developing a new transdermal system. In addition, the mechanism by which the terpene/PG system enhanced the skin permeation of LOM was elucidated in detail using attenuated total reflection-Fourier transform infrared spectroscopy (ATR-FTIR), confocal laser scanning microscopy (CLSM) and small angle X-ray scattering (SAXS).

\section{MATERIALS AND METHODS}

\section{Materials}

LOM was purchased from LKT Laboratories, Inc. (St. Paul, MN, USA). PG, 1,8-cineole, $l$-menthol and menthone were purchased from Wako Pure Chemical Industries, Ltd. (Osaka, Japan). Tween 80 
was purchased from Kanto Chemical Industry Co., Ltd. (Tokyo, Japan). $\alpha$-Pinene oxide, linalool, trypsin (type II-S),1,1'[-]Dioctadecyl[-]3,3,3',3'tetramethyl-indocarbocyanine perchlorate (DiI) and 9 - (Diethylamino) - 5H[-]benzo [ $\alpha$ ] phenoxazin-5one (Nile Red) were purchased from Sigma Aldrich (St. Louis, MO, USA). All other solvents and reagents were commercial products of analytical grade and were used without further purification. Figure 2 shows the chemical structures and physicochemical properties of various terpenes which were used in this study.

\section{Skin permeation studies}

All animal experiments were carried out in accordance with the guidelines of the Institutional Animal Care and Use Committee (School of Pharmacy, Nihon University, Chiba, Japan). The full-thickness dorsal skin of male hairless mice (510 weeks of age), sacrificed by ether, was excised and adherent fat and other visceral debris were removed from the undersurface. In vitro skin permeation studies were carried out with Franz cells (Vertical diffusion cell ${ }^{\mathrm{TM}}$, Hanson Research Corporation, CA, USA). Franz cells were mounted in a Microette ${ }^{\mathrm{TM}}$ Plus system (Hanson Research) equipped with a thermostatic bath, injection system, vacuum pump, agitation clamp, archive samples in Mulitfull $^{\mathrm{TM}}$ collector, and autosampler. 1\% LOM solution $(200 \mu \mathrm{L})$ in PG with or without various terpenes $(10 \% \mathrm{w} / \mathrm{w})$ was added to the donor cell. The effective area of diffusion was $1.77 \mathrm{~cm}^{2}$, and the receiver cell volume was $7 \mathrm{~mL}$. The receiver cell was filled with Tween $80(0.5 \% \mathrm{w} / \mathrm{w})$ in $0.9 \% \mathrm{NaCl}$ solution to give sink conditions (26) and stirred at $650 \mathrm{rpm}$ using a magnetic stirrer. The entire system was maintained at $32 \pm 0.5{ }^{\circ} \mathrm{C}$ with a circulating water jacket. The amount of LOM that permeated the skin into the receiver cell was quantitated by collecting $0.5 \mathrm{~mL}$ samples from the receiver cell at the designated time intervals, and analyzing these by HPLC. The volume of receiver cell fluid withdrawn at each interval was replaced with Tween $80(0.5 \%$ $\mathrm{w} / \mathrm{w}$ ) in $0.9 \% \mathrm{NaCl}$ solution.

\section{Analytical method}

The HPLC system comprised a PU-2080 plus intelligent HPLC pump, a UV-2075 intelligent UV/VIS detector, a CO-2065 plus intelligent column oven, an AS-2055 plus intelligent sampler and a ChromNAV chromatography data system (all from JASCO Co., Tokyo, Japan). The analytical column, an Inertsil C8-3 (150 $\mathrm{mm} \times 4.6 \mathrm{~mm}$ i.d.; particle size $5 \mu \mathrm{m}$; GL Sciences Inc., Tokyo, Japan) was used at $50{ }^{\circ} \mathrm{C}$. The mobile phase consisted of $0.05 \mathrm{M}$ potassium dihydrogen phosphate $(\mathrm{pH} 2.5)$ and acetonitrile $(58: 42, \mathrm{v} / \mathrm{v})$ at a flow rate of $1.0 \mathrm{~mL} / \mathrm{min}$. The column eluate was monitored using an ultraviolet wavelength of $225 \mathrm{~nm}$.

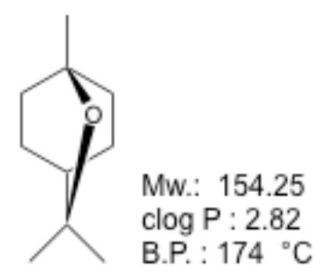

1,8-Cineole

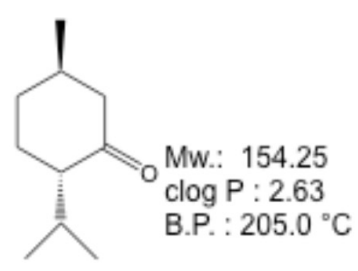

Menthone

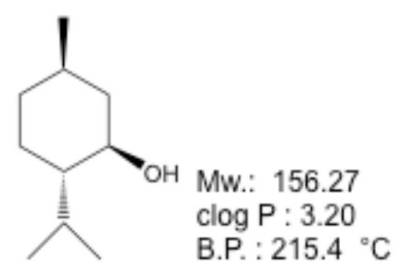

I-Menthol

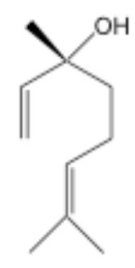

Linalool

Mw.: 154.25

$\operatorname{cog} P: 3.28$

B.P. : $198.5^{\circ} \mathrm{C}$

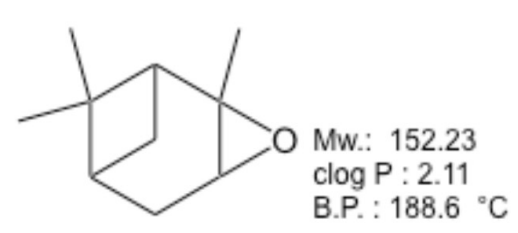

$\alpha$-Pinene oxide

Linalool

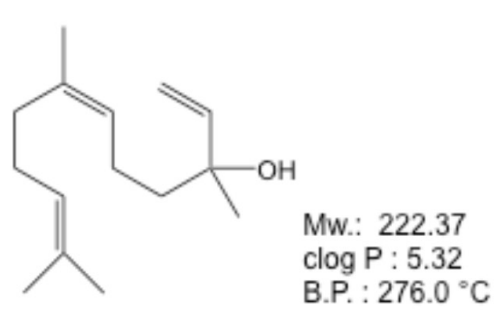

Nerolidol

B.P. : Boiling point

Figure 2. Chemical structures and physicochemical properties of various terpenes used in this study 


\section{DATA ANALYSIS}

The cumulative amount of drug that had permeated through the skin was plotted as a function of time. The steady state flux was then calculated from the slope of the linear region of this plot and expressed as $\left(\mu \mathrm{g} / \mathrm{cm}^{2} / \mathrm{h}\right)$. The lag time (h) was calculated by extrapolating the linear region of the curve to the $\mathrm{X}$ axis.

\section{ATR-FTIR spectroscopic studies}

The hairless mouse skin for ATR-FTIR spectrometry studies was prepared in the same method as "Skin permeation studies" section. Namely, the hairless mouse skin prepared as described above was soaked in PG with or without $10 \% \mathrm{w} / \mathrm{w}$ various terpenes at $32{ }^{\circ} \mathrm{C}$ for $24 \mathrm{~h}$. The treated skin samples were washed with distilled water and blotted dry. The infrared spectra of skin samples were obtained using Fourier transform infrared spectroscopy (FTIR-230 spectrometer, JASCO Co.) with an attenuated total reflection (ATR) unit (ATR-500/M, JASCO Co.). The spectrum recorded represents an average of 32 scans obtained with a resolution of $2 \mathrm{~cm}^{-1}$ at room temperature. The spectra were collected in the wavenumber range of $4000-400 \mathrm{~cm}^{-1}$. The internal reflectance element (IRE) used in this study was a zinc selenide trapezoid having $45^{\circ}$ entrance and exit faces. Skin was carefully mounted on the IRE.

\section{Localization of hydrophobic fluorescence probes (Nile Red and DiI) in the skin}

This procedure was carried out in a similar manner to that reported previously (27). The procedure was the same as for the regular skin permeation study described above. Briefly, $200 \mu \mathrm{L}$ of Nile Red or DiI $(10 \mu \mathrm{M})$ solution in PG with or without $10 \% \mathrm{w} / \mathrm{w}$ various terpenes were added to the donor cell. The receiver cell was filled with Tween $80(0.5 \% \mathrm{w} / \mathrm{w})$ in $0.9 \% \mathrm{NaCl}$ solution. The skin was fixed with $20 \%$ formalin neutral buffer solution $8 \mathrm{~h}$ after the application of donor solution containing the fluorescein probe. Next, the surface of the skin was observed using CLSM (LSM 510, Carl Zeiss Co. Ltd., Tokyo, Japan). All samples were excited at 488 (Nile Red) or $543 \mathrm{~nm}$ (DiI) and X-Z sectioning was used to determine the depth of permeation using a $40 \times$ objective lens. The skin surface $(Z=0 \mu \mathrm{m})$ was defined by the user as the brightest fluorescence image with morphological characteristics of the SC surface (28).

\section{Preparation of SC samples}

SC was separated from hairless mouse skin by digestion with $0.1 \% \mathrm{w} / \mathrm{v}$ trypsin in PBS solution $(\mathrm{pH}$ 7.4) at $32{ }^{\circ} \mathrm{C}$ for $12 \mathrm{~h}$. The SC was then rinsed in distilled water and dried under vacuum using a rotary pump. Dry SC was soaked in PG with/without 1,8 -cineole $(10 \% \mathrm{w} / \mathrm{w})$ solution at $32{ }^{\circ} \mathrm{C}$ for $24 \mathrm{~h}$. The treated SC was carefully wiped using a KimWipe $^{\circledR}$ and then dried under vacuum using a rotary pump for $12 \mathrm{~h}$. Before use, the SC was hydrated to give a water content varying between 30 $40 \% \mathrm{w} / \mathrm{w}$. Water content is defined as: [(weight hydrated SC-weight dry SC) / weight hydrated SC] $\times 100$. Untreated SC samples served as controls.

\section{Small angle $X$-ray scattering measurement}

SAXS measurements of treated SC samples were performed using a NanoSTAR instrument (Bruker AXS, WI, USA) with a $\mathrm{Cu}-\mathrm{K} \alpha$ radiation source operating at $45 \mathrm{kV} / 120 \mathrm{~mA}$. The wavelength $(\lambda)$ of the X-ray beam was $0.155 \mathrm{~nm}$. The sample SC (approximately $10 \mathrm{mg}$ ) was held in an aluminum sample holder, which was sealed with Kapron films on both sides. The sample to detector distance was set to $106 \mathrm{~cm}$. Scattering intensity was plotted as function vector $S$, defined as $S=(4 \pi \sin \theta / \lambda)$, in which $\lambda$ and $\theta$ are wavelength and scattering angle, respectively. The position of the diffraction peaks in the $S$ space are directly related to the periodicity $(d)$ of the molecular structure (in real space), as defined in Braggs law where $2 d \sin \theta=n \lambda$, in which $n$ is the order of the diffraction peak. The different diffraction orders are equidistant in the $S$ space, as shown by the equation $S n=2 n \pi / d$, in which $S_{n}$ is the position of the diffraction peak order $n$.

\section{STATISTICAL ANALYSIS}

The results were analyzed by one-way analysis of variance (ANOVA), followed by the modified Fisher's least-squares difference method. The level of statistical significance was set at $\mathrm{p}<0.05$.

\section{RESULTS}

\section{Skin permeation studies}

Table 1 depicts the skin permeation parameters of LOM with various terpenes in PG solution. At $10 \%$ $\mathrm{w} / \mathrm{w}$ concentration in $\mathrm{PG}$ solution, all terpenes enhanced the steady state flux of LOM, whereas no enhancement was observed with PG alone (Figure 3). Among the terpenes, the highest permeation rate of $28.8 \mu \mathrm{g} / \mathrm{cm}^{2} / \mathrm{h}$ was observed with 1,8 -cineole, while nerolidol produced the lowest enhancement in LOM flux $\left(14.2 \mu \mathrm{g} / \mathrm{cm}^{2} / \mathrm{h}\right)$. 


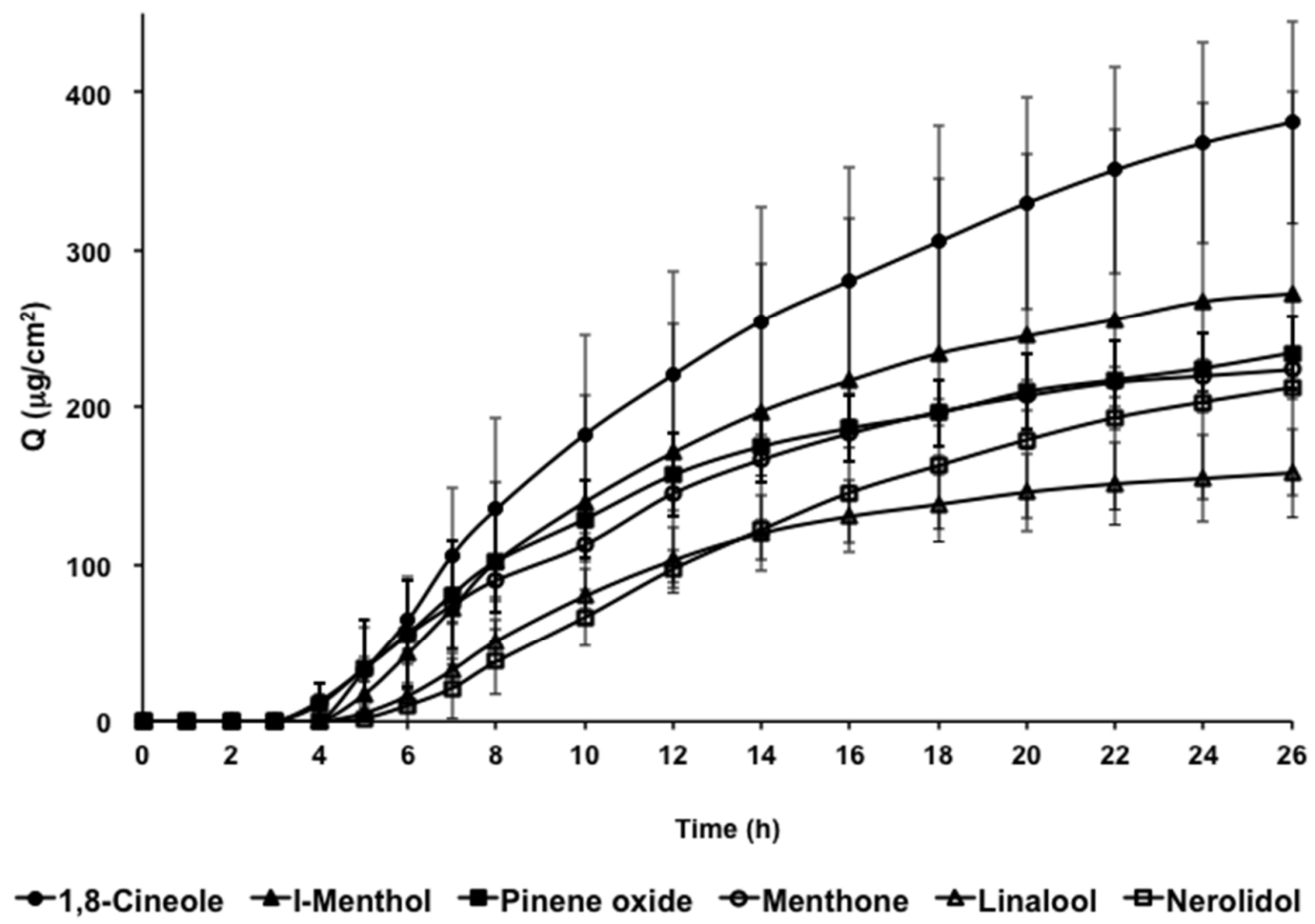

Figure 3. Skin permeation profiles of LOM with various terpenes in PG solution. Q, Cumulative amount of LOM; Data are represented as mean $\pm \mathrm{SD}$ values $(\mathrm{n}=3-4)$

Table 1. Skin permeation parameters of LOM with various terpenes

\begin{tabular}{lccc}
\hline \multicolumn{1}{c}{ Terpene } & $\begin{array}{c}\text { Flux } \\
\left(\mu \mathrm{g} / \mathrm{cm}^{2} / \mathrm{h}\right)\end{array}$ & $\begin{array}{c}\text { Lag time } \\
(\mathrm{h})\end{array}$ & $\begin{array}{c}\text { Q at } 26 \mathrm{~h} \\
\left(\mu \mathrm{g} / \mathrm{cm}^{2}\right)\end{array}$ \\
\hline PG only & 0.0 & - & 0.0 \\
$+1,8$-Cineole & $28.8 \pm 8.5$ & $3.9 \pm 0.5$ & $381.1 \pm 64.1$ \\
$+l$-Menthol & $28.4 \pm 6.6$ & $4.5 \pm 0.1$ & $272.4 \pm 128.5$ \\
$+\alpha$-Pinene oxide & $23.1 \pm 1.9$ & $3.6 \pm 1.3$ & $234.5 \pm 23.7$ \\
+ Menthone & $20.6 \pm 2.5$ & $3.4 \pm 0.2$ & $223.8 \pm 11.1$ \\
+ Linalool & $16.6 \pm 4.1$ & $4.8 \pm 0.6$ & $158.3 \pm 28.1$ \\
+ Nerolidol & $14.2 \pm 3.0$ & $5.0 \pm 2.2$ & $212.6 \pm 7.3$
\end{tabular}

Q, Cumulative amount of LOM; +, includes PG and the stated compound; Data are represented as mean \pm SD values, $n=3-4$.

\section{ATR-FTIR studies}

To elucidate the effect of terpenes on the intercellular lipids in the (SC), ATR-FTIR stretching peaks near $2850 \mathrm{~cm}^{-1}\left(\mathrm{CH}_{2}\right.$ symmetric stretching absorbance frequency peak) and $2920 \mathrm{~cm}^{-1}\left(\mathrm{CH}_{2}\right.$ asymmetric stretching absorbance frequency peak) (29) were measured before and after the application of PG or a combination of terpene/PG to hairless mouse skin (Figure 4). These bands are due to the methylene groups of the (SC) lipid alkyl chains. It has been demonstrated that enhancers which cause a shift to a higher $\mathrm{CH}_{2}$ stretching frequency improve drug permeation (30). Peaks near $2920 \mathrm{~cm}^{-1}$ and $2850 \mathrm{~cm}^{-1}$, for asymmetric and symmetric stretching, respectively, showed that treatment of skin with PG alone did not result in a significant shift in stretching frequencies compared with untreated skin. In contrast, in skin treated with a combination of terpenes/PG, shifts were observed to $\mathrm{CH}_{2}$ symmetric and asymmetric stretching frequencies which were approximately 2 to $6 \mathrm{~cm}^{-1}$ higher than those observed with no treatment or with PG alone. 
(A) 1,8-Cineole

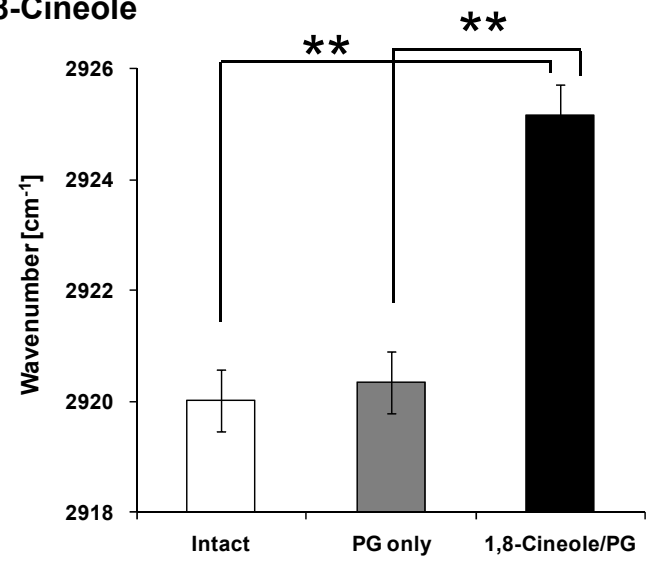

(B) I-menthol

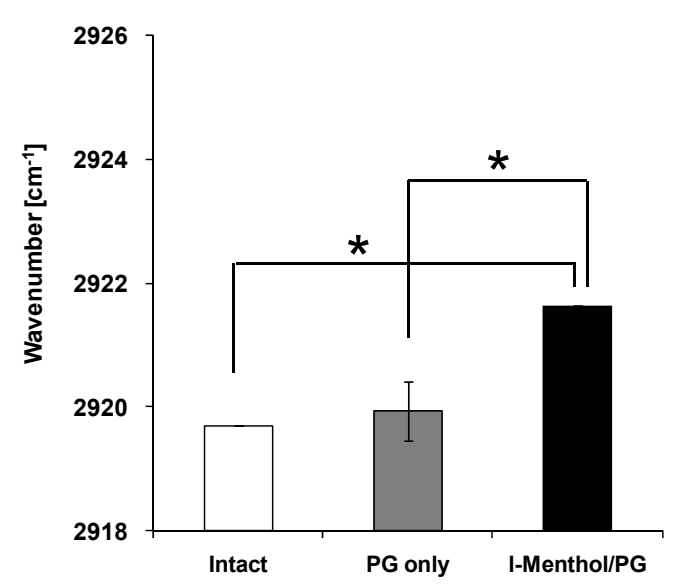

(C) $\alpha$-Pinene Oxide

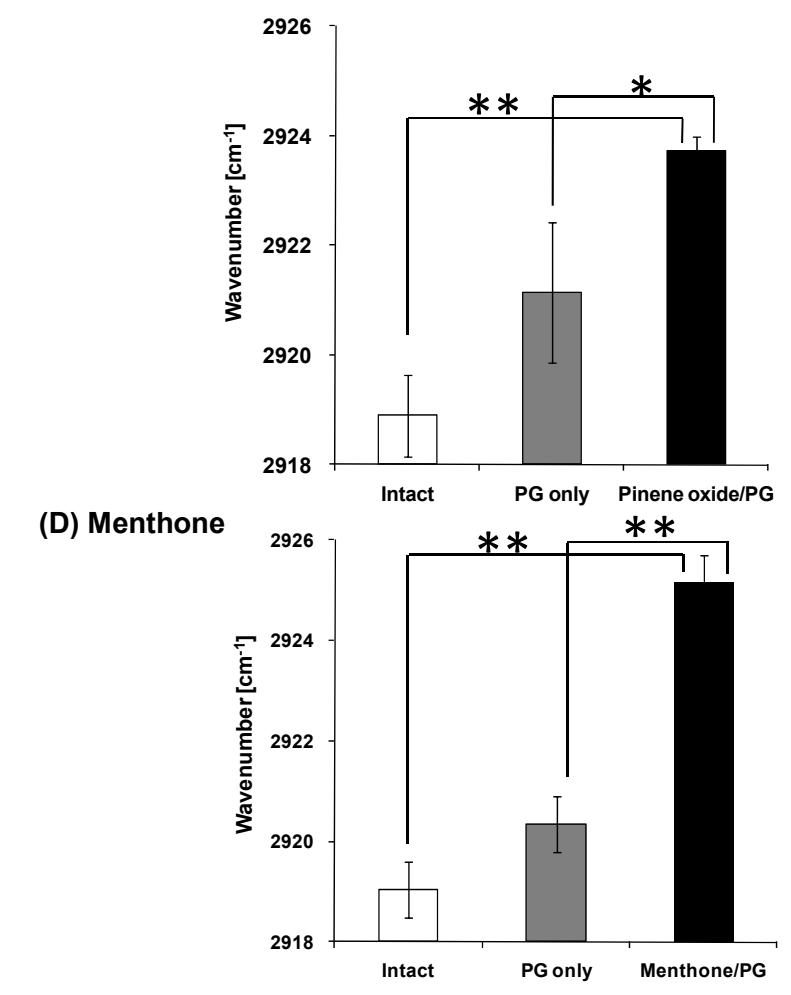

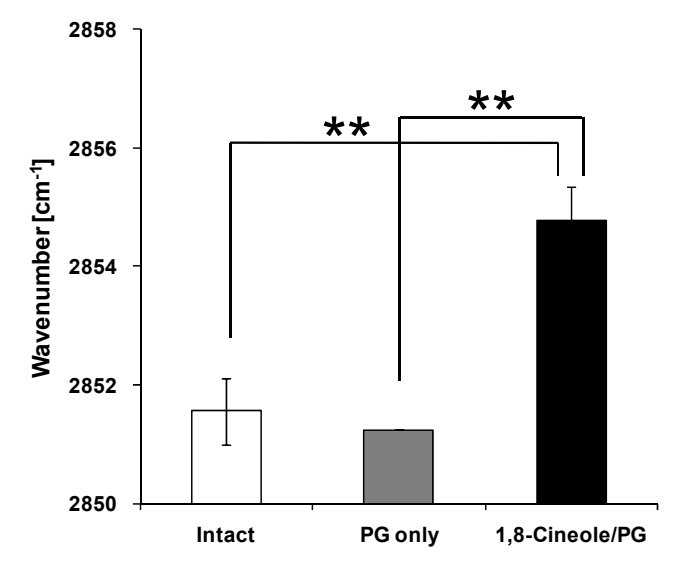

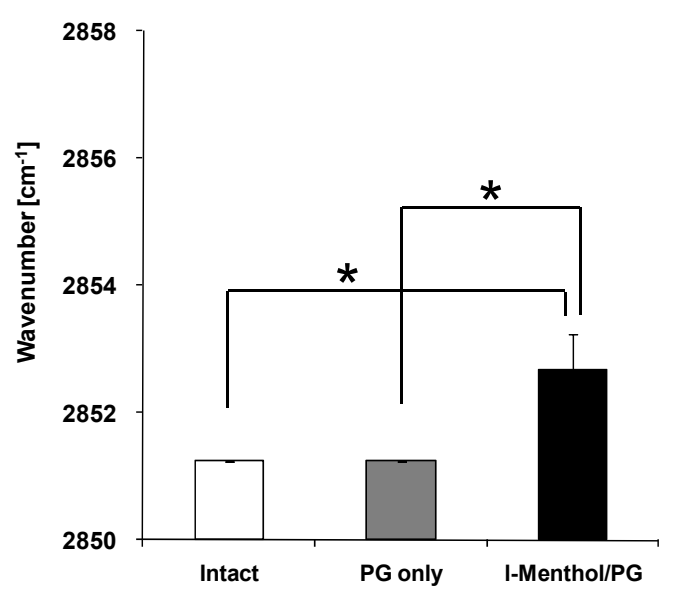

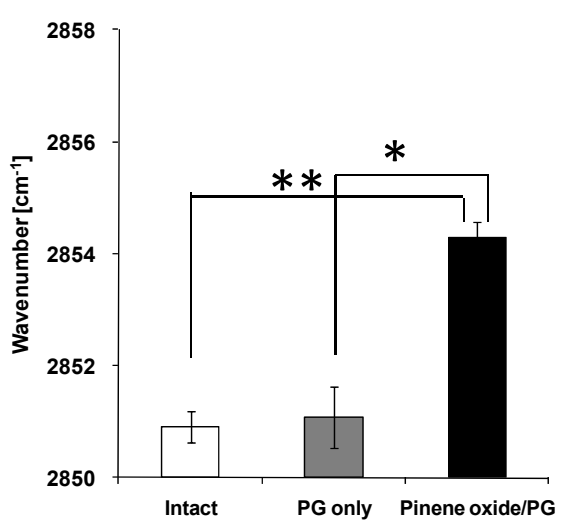

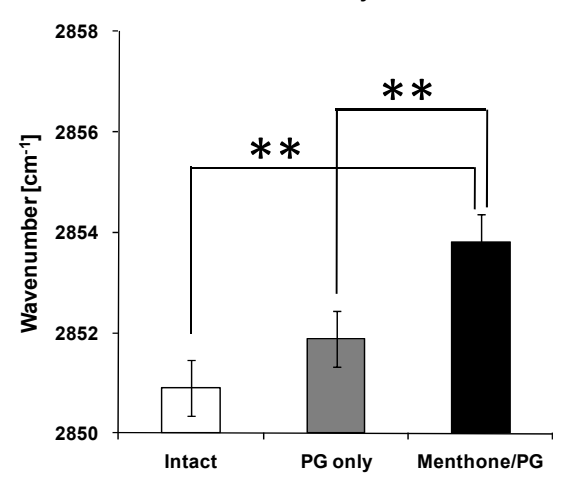


(E) Linalool
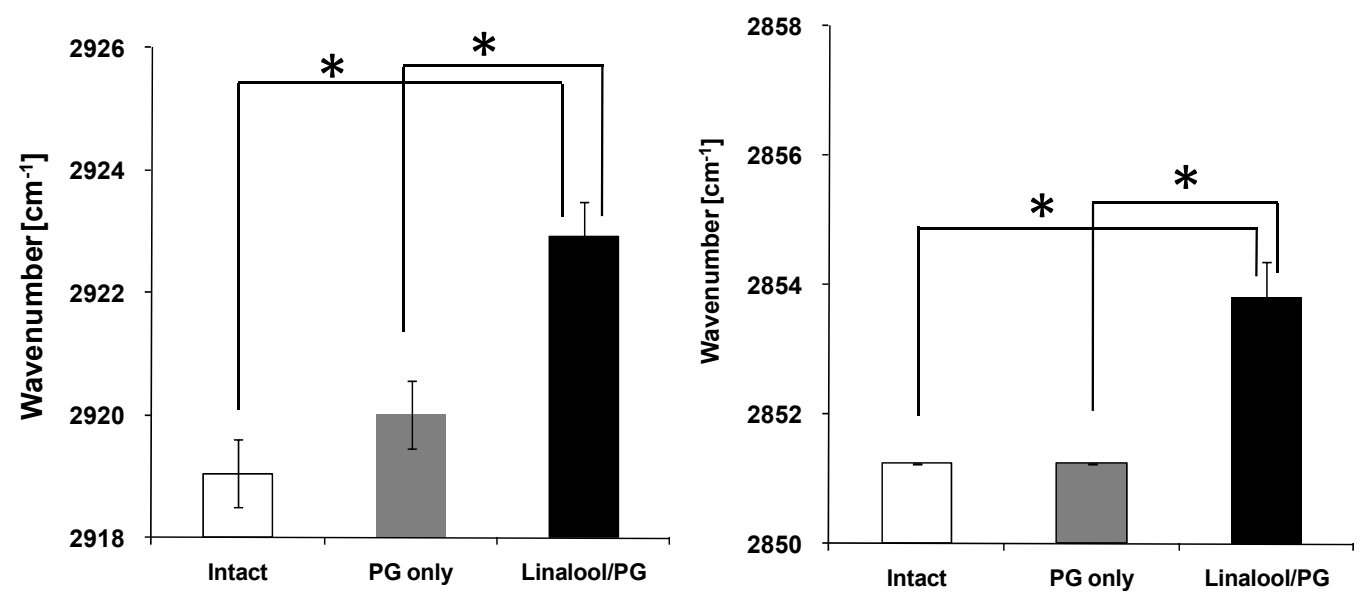

Figure 4. Effect of PG with/without various terpenes (1,8-Cineole (A), $l$-Menthol (B), $\alpha$-Pinene oxide (C), Menthone (D), or Linalool (E)) on C-H asymmetric (left-hand graphs) and symmetric (right-hand graphs) stretching frequencies. Data are represented as mean $\pm \mathrm{SD}$ values $(\mathrm{n}=3), * * \mathrm{p}<0.01,{ }^{*} \mathrm{p}<0.05$ (ANOVA).

\section{CLSM studies}

In this study, CLSM was used to clarify the site of action of $\mathrm{PG}$ and terpenes/PG in the SC. Figures 5(A) and (B) show confocal images treated with Nile Red and DiI respectively, obtained from PG- and terpene/PG-treated samples of hairless mouse skin. Lipophilic fluorescent probes (Nile Red or DiI) in PG solutions with and without terpenes were administered to an in-focus XY plane (parallel to the skin surface) for $8 \mathrm{~h}$. When Nile Red or DiI were applied in PG solution, no fluorescence was detected on the surface of the SC. In contrast, the distribution of fluorescence into the intercellular space and around the corneocytes was increased remarkably by the addition of terpenes to the donor solution compared with treatment with PG alone.

\section{SAXS studies}

To elucidate the effect of 1,8-cineole, the most effective enhancer of LOM permeation in the skin permeation study, on the structure of SC lipids, we carried out SAXS measurements on hairless mouse SC. SAXS measurement of untreated SC hydrated to approximately $40 \% \mathrm{w} / \mathrm{w}$ revealed $1^{\text {st }}$ to $4^{\text {th }}$ order diffraction of approximately $14 \mathrm{~nm}$ lamellar spacing $\left(d=14,6.7,4.5\right.$, and $3.3 \mathrm{~nm}$ from $1^{\text {st }}$ to $4^{\text {th }}$ order diffraction, respectively) (Figure 6(A)). This is in close accordance with results from synchrotron $\mathrm{X}$ ray diffraction published by other authors $(31,32)$. The SAXS profile of hairless mouse skin treated with PG was almost identical to that of the untreated skin (Figure 6(B)). In contrast, the scattering peak of SC prepared using 1,8-cineole/PG was broad and very weak in intensity (Figure 6(C)).

\section{DISCUSSION}

\section{Skin Permeation studies}

There is few report that be concerned in transdermal delivery of antimigraine drug. Sumatriptan succinate is a selective serotonin 5- $\mathrm{HT}_{1 \mathrm{~B} / 1 \mathrm{D}}$ agonist used in the treatment acute migraine episodes and it is available in several dosage forms including subcutaneous injection, oral, and nasal delivery. Patel et al. reported that the transdermal delivery of sumatriptan is feasible using an iontophoretic patch system (33). They showed that the in vivo results indicated that the pharmacokinetics following transdermal iontophretic delivery were similar to those seen after oral nasal, and rectal delivery. But, the iontophoresis technique is not convenient due to use the special equipment. In contrast, improving percutaneous absorption of drug using chemical enhancer is a simple and cheap method. In pre-study, we examined the enhancing effect of the skin permeation of LOM with the combination of PG and various enhancers. All enhancers such as isopropyl myristate, carboxylic acids, non-ionic surfactants, alcohols, urea and terpenes were used for their enhancing effects on the percutaneous absorption of various drugs. Of all enhancers used in this screening, the PG solvent system containing terpenes markedly enhanced LOM permeation through the skin. In contrast, no significant enhancing effects were observed with other enhancers. 
(A) Nile red

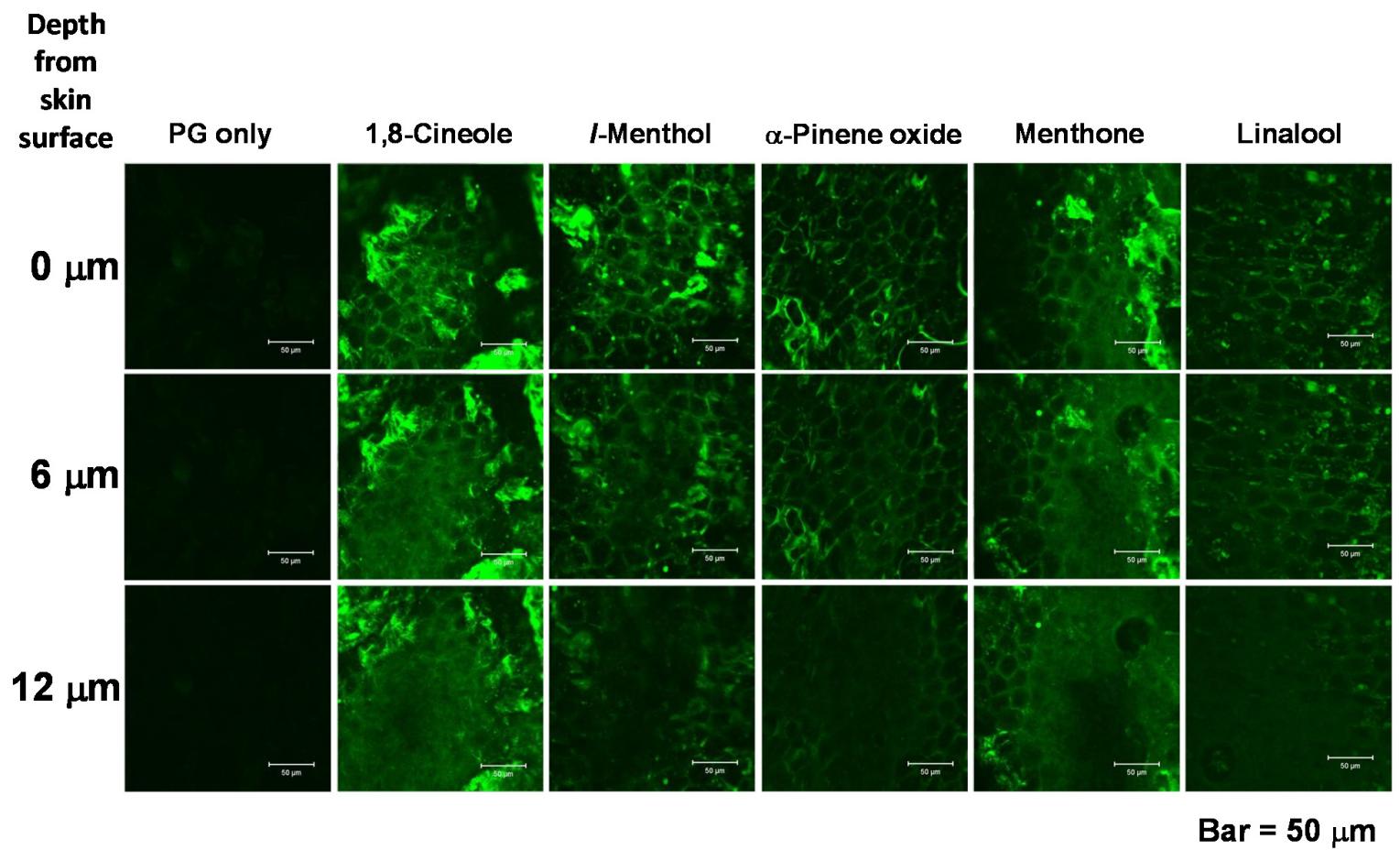

(B) Dil

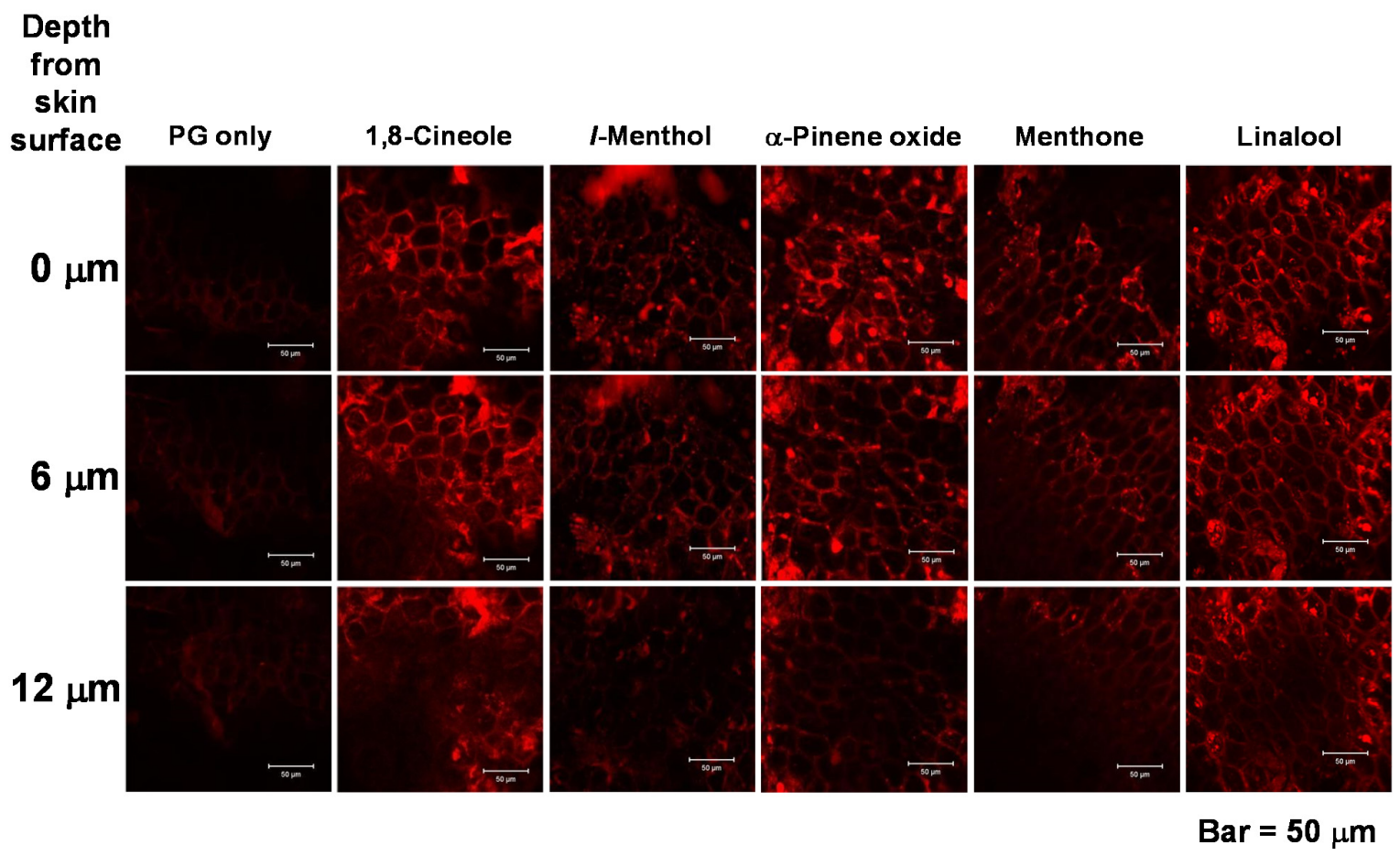

Figure 5. Confocal fluorescence images of hairless mouse skin to which Nile Red (A) or DiI (B) were administered for $8 \mathrm{~h}$ 


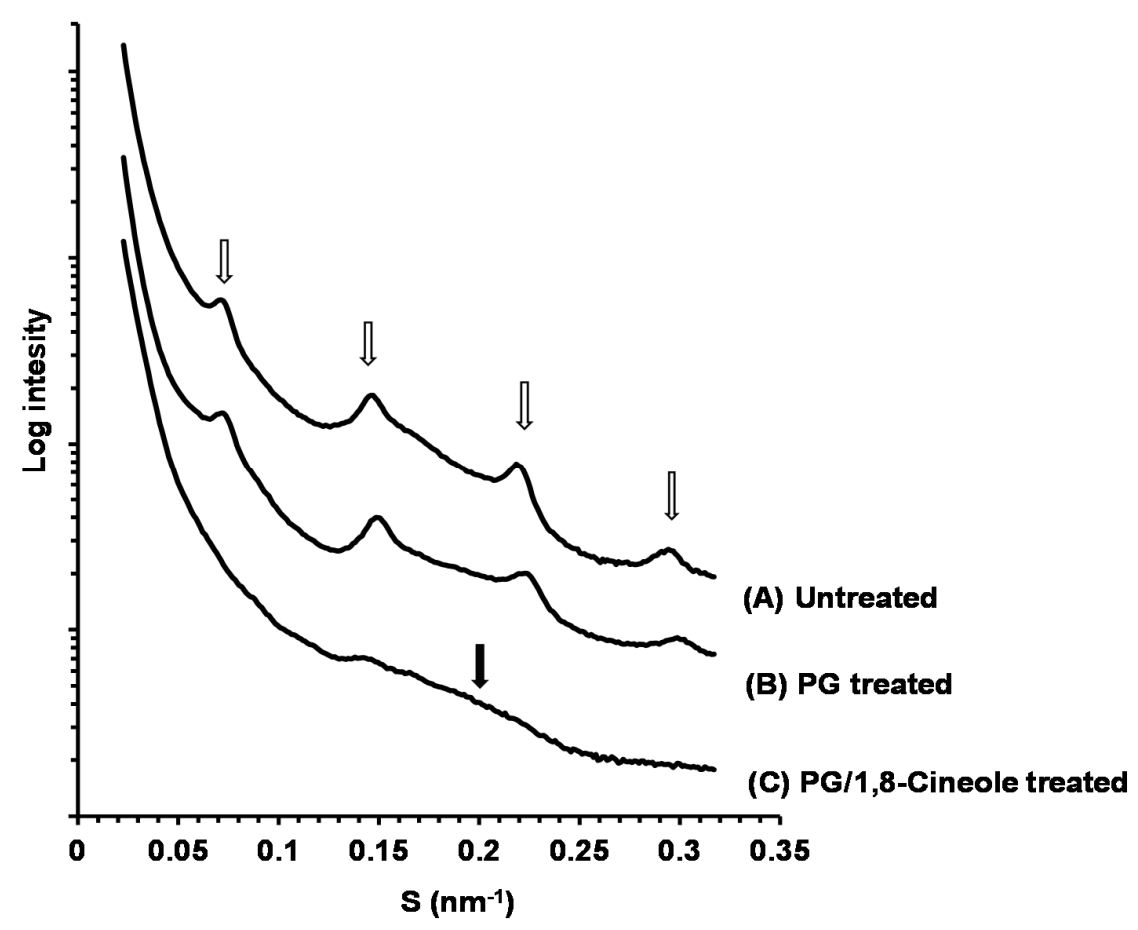

Figure 6. The scattering curves of untreated SC (A), SC treated with PG (B) and SC treated with a combination of PG and 1,8-Cineole $(C)$. Open arrows indicate the $1^{\text {st }}$ to $4^{\text {th }}$ order diffraction peaks for the long lamellar structure of untreated SC and the closed arrow indicates the diffraction peak of SC treated with PG and 1,8-Cineole.

Terpenes, neat or combination with cosolvents have been investigated as skin permeation enhancers for both lipophilic (34) and hydrophilic drugs (35) through human skin.

Skin permeation studies result revealed that terpenes/PG enhanced the skin permeation of LOM, with the highest permeation rate of $28.8 \mu \mathrm{g} / \mathrm{cm}^{2} / \mathrm{h}$ observed with 1,8-cineole. However, it was not clear whether the different efficacies of skin permeation enhancement were dependent upon certain characteristics of the terpenes. The enhancement of skin permeation of a drug often depends on physicochemical characteristics of the enhancer molecule, such as $\log \mathrm{P}$, boiling point, and hydrophilic-lipophilic balance (HLB). In particular, a previous report indicated that since they are volatile compounds, the boiling points of terpenes play a major role in their enhancement of the permeability of zidovudine (36). It was reported that low boiling point's terpene like cineole $\left(174{ }^{\circ} \mathrm{C}\right)$ enhanced the skin permeation of zidovudine than that of carvone $\left(230^{\circ} \mathrm{C}\right)$. Furthermore, Jain et al. showed that the similar result of skin permeation of imipramine hydrochloride using by terpenes (37).

We investigated the relationships between the flux of LOM through the skin and various physical properties of the terpenes used as permeation enhancers. Figure 7 depicts the relationships between the flux of LOM and molecular weight (A), clog P (B) (38), and boiling point (C) of several terpenes used in the present study. The physicochemical parameters of all terpenes used in this study, except nerolidol, can be grouped as having molecular weight over $150, \operatorname{clog} \mathrm{P}$ under 3.3 and boiling point over $170{ }^{\circ} \mathrm{C}$, but the correlation coefficients between the physicochemical parameters of terpenes and the flux of LOM all fell below 0.64 . Hence, no clear relationship was found between the physicochemical parameters of specific terpenes and their ability to enhance the skin permeation of LOM. From the view of structure's feature of terpenes used in this study, nerolidol is a kind of sesquiterpenes, and the others are of monoterpenes. Nerolidol is the least enhancement effect among the terpenes used in this study. It was considered that sesquiterpenes, probably due to a more bulky molecular structure, tend to be less effective and favorable. They are less active and have a long duration of action implying poor reversibility, i.e., they do wash out of the skin readily. However, Nokhodchi et al reported that sesquiterpenes (farnesol, nerolidol) were found to be more potent enhancers than monoterpenes (carvone, limonene oxide) for diclofenac sodium (39). Therefore, we did not find the clear structure-activity relationship. 

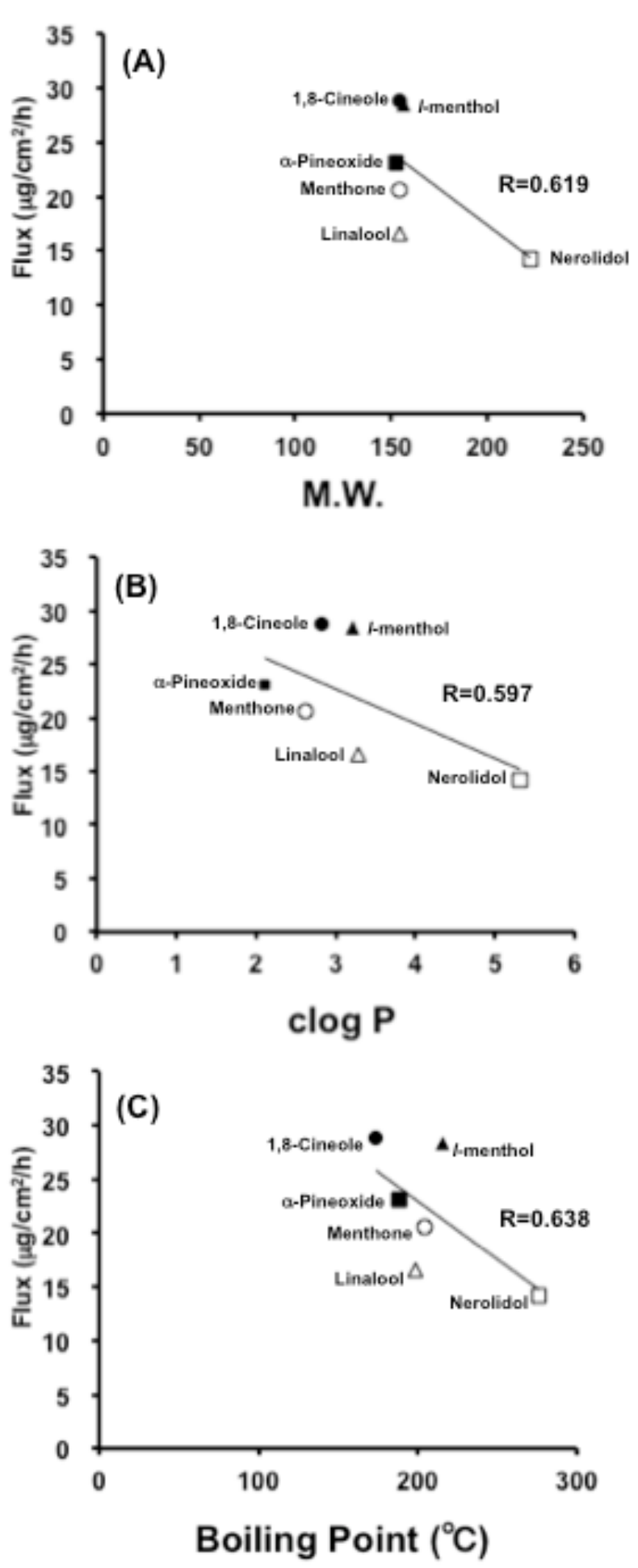

Figure 7. The relationships between flux of LOM and molecular weight (A), clog P (B) or boiling point (C) of various terpenes

\section{ATR-FTIR studies}

ATR-FTIR is a powerful method for analyzing SC structure from a biophysical standpoint. This technique allows greater understanding of the mechanism by which various permeation enhancers alter the barrier function of the SC; through molecular characterization of its lipid, protein and water content, analysis of the drug penetration pathway, and identification of the biochemical modifications induced by penetration (40-43). The major advantage is that this technique enables the elucidation of the extent and mechanism of percutaneous absorption enhancement in vitro and in vivo (44).

The peaks obtained near 2920 and $2850 \mathrm{~cm}^{-1}$ correspond to asymmetric and symmetric stretching modes, respectively, of the terminal methylene groups of the lipids, and these provided specific information about the interior composition of the lipid bilayer (29). The incorporation of ceramides, cholesterol, fatty acids, cholesterol esters, and cholesterol sulfate into the lipid lamellae confer barrier properties to the SC. The trans/gauche ratio of the alkyl tails influence the frequencies of the FTIR bands. The band positions for symmetric and asymmetric peak stretching represent the stable trans form. A change in the band position from trans to gauche conformation indicates fluidization of the lipid bilayer. Fluidization of SC lipids enhances the permeation of drugs. The magnitude of blue shift in the peak frequency of the asymmetric and symmetric stretching vibration absorbance is correlated with an increased number of gauche conformers in the lipid acyl chain (rotamer disordering). The higher the shifts, the higher the ratio of gauche to trans.

It has been demonstrated that promoters causing a higher shift in $\mathrm{CH}_{2}$ stretching frequency improve drug permeation most. Analysis of peaks near 2920 and $2850 \mathrm{~cm}^{-1}$ for asymmetric and symmetric stretching, respectively, showed that treatment of skin with PG resulted in a shift to frequencies which were not significantly higher than those in untreated skin. It has been reported that PG interacts predominantly with keratins in the SC and does not significantly alter SC lipid organization. Our results were consistent with previous findings (45). In contrast, in skin treated with a combination of terpenes and $\mathrm{PG}$, higher frequency shifts in $\mathrm{CH}_{2}$ symmetric and asymmetric stretching were observed than with PG alone. This increased lipid fluidity after combination treatment with terpenes and PG was likely responsible for the enhanced permeability of LOM through hairless mouse skin.

We suggest that the molecular basis of these permeability changes is lipid fluidization. Normally, hydrocarbons within the lipid domain of the SC below their transition temperature exist in a trans conformation. When the lipid domain becomes fluidized by thermal induction (46) and/or by treatment with chemical enhancer(s), an increase in 
the wavenumber of $\mathrm{CH}_{2}$ frequency would occur due to increased motional freedom and numbers of gauche conformers of lipid alkyl chains (47). Therefore, this increased lipid fluidity after combination treatment with terpenes and PG might be responsible for the enhanced permeability of LOM through hairless mouse skin.

\section{CLSM studies}

CLSM has become a well-established technique for obtaining high-resolution images from biological and other specimens (48). The advantage of CLSM is its high resolution and the option of omitting tissue fixation, thereby avoiding label delocalization during sample preparation. Furthermore, the label distribution can be visualized in deeper layers of the skin using optical cross-sections. Visualization of fluorescence "hotspots" by CLSM is therefore a valuable method for examining the extent of skin permeation of various molecules and for identifying the pathways by which they are transported (49).

CLSM was used to identify the site of action of PG and terpenes/PG in the SC. Because CLSM studies give qualitative data, both Nile Red and DiI were employed as lipophilic fluorescent probes in order to assess reproducibility. Nile Red is an uncharged phenoxazone dye whose fluorescence properties are altered by the effective polarity of its environment (50). DiI is one of the long-chain carbocyanine dyes. Two long alkyl chains attached to the fluorophore determine its affinity for the membrane. Carbocyanine dyes with short alkyl chains partition between the aqueous and membrane phases in a membrane-potential-dependent manner, while the hydrophobic nature of long-chain carbocyanine dyes leads to their insertion into cells with their alkyl chains embedded in the lipid bilayer (51). Both fluorescent probes are used for visualization of the intercellular spaces in the SC (52, 53).

In mouse skin treated with Nile Red or DiI in PG solution, absorption of the dyes was poor, and no fluorescence was detected within the SC. This suggests that PG did not affect SC intracellular lipids. However in skin treated with fluorescence probes in PG solution with terpenes, permeation of the fluorescence probes was increased and the shape of the corneocytes could be distinguished at the surface of the SC. Furthermore, the fluorescent probes were also detected in the deeper skin tissues when applied with terpenes in PG solution.

Taken together with the ATR-FTIR findings, it is likely that the combined application of terpenes and PG affects the SC lipids, causing the tightly packed intercellular lipid in the SC to become disordered. Therefore, the percutaneous absorption of lipophilic drugs such as LOM would be promoted by the combination of terpenes used in this study with PG.

\section{SAXS studies}

Understanding the structure of the intercellular lipid matrix of the SC is important in order to elucidate the mechanism involved in the percutaneous absorption of drugs. Intercellular lipids form multilamellar structures, which have been observed by SAXS (54) and electron microscopy (55).

Using SAXS, we revealed the effect of PG or a combination of 1,8-cineole/PG on the multilamellar structures of SC lipids. It was reported that the multilamellar structures in the SC were classified mainly into long lamellar structures with repeat distances of approximately 13-14 nm and, a scattering peak position for 1st to 4th order diffraction of approximately 13-14 $\mathrm{nm}$ was not observed in untreated SC. Ohta et al. reported that with increased water content up to approximately $30 \%$, the diffraction peak positions for long lamellar structures are almost unchanged, although the sharpness of these peaks depended on water content (32). Therefore, for the following experiments, SAXS measurements were carried out on samples with a water content of approximately $30-40 \% \mathrm{w} / \mathrm{w}$.

Pretreatment with PG did not alter the peak profile of intact SC. This suggests that PG may not affect the stacking arrangement of the lipid bilayers. In contrast, SAXS measurements showed that in SC treated with a combination of 1,8-cineole and PG, the scattering peak of SC was broad and very weak in intensity. This suggested that the combination of 1,8-cineole and PG may cause disorder of the stacking arrangement of the lipid bilayers.

\section{CONCLUSIONS}

In this study, we demonstrated that a combination of terpenes and PG enhanced the skin permeability of LOM. 1,8-cineole showed the greatest enhancement effect on the percutaneous absorption of LOM among the terpenes examined. ATR-FTIR measurements revealed that the combination of terpenes and PG affects the SC lipids, causing the tightly packed intercellular lipid in the SC to become disordered. The extent of penetration of the lipophilic fluorescence probes Nile Red and DiI were measured by CLSM, in in vitro skin permeation studies, using PG or terpenes/PG as skin permeation enhancers. When administered with $\mathrm{PG}$ alone, no fluorescence probe was observed to permeate significantly into the skin. In contrast, when applied with terpenes in PG, both fluorescence probes were distributed into the intercellular space 
between the corneocytes and were also detected in the deeper layers of the skin. SAXS measurements showed that the combination of PG and 1,8-cineole affects the SC lipids, causing the tightly packed intercellular lipid in the SC to become disordered.

Taken together, these results indicate that terpene/PG systems are effective enhancers of the flux of LOM, which is a highly lipophilic drug, and that terpene/PG systems have potential application as a new TDDS.

\section{ACKNOWLEDGEMENTS}

This study was supported by a Grant-in-Aid for Scientific Research from the Ministry of Education, Culture, Sports, Science, and Technology of Japan. The authors are grateful to Dr. Kozo Takayama of Hoshi University, for his excellent technical advice. The authors thank Mr. Kubobuchi (Nissan Arc, LTD.) for SAXS measurements, and Ms. Mariko Adachi and Mr. Masato Yamashita for their technical assistance in the experimental work.

\section{REFERENCES}

1. Lipton RB, Stewart WF, Diamond S, Diamond ML, Reed M. Prevalence and burden of migraine in the United States: data from the American Migraine Study II. Headache. 2001; 41: 646-57.

2. Sakai F, Igarashi H. Prevalence of migraine in Japan: a nationwide survey. Cephalalgia : an international journal of headache. 1997; 17: 15-22.

3. Kurth T, Gaziano JM, Cook NR, Bubes V, Logroscino G, Diener HC, Buring JE. Migraine and risk of cardiovascular disease in men. Arch Intern Med. 2007; 167: 795-801.

4. Hara H, Morita T, Sukamoto T, Cutrer FM. Lomerizine (KB-2796), a new antimigraine drug. CNS Drug Rev. 1995; 1: 204-26.

5. Imai N, Konishi T, Serizawa M, Okabe T. Do the effects of long-term lomerizine administration differ with age? Intern Med. 2007; $46: 683-4$.

6. Finnin BC, Morgan TM. Transdermal penetration enhancers: applications, limitations, and potential. J Pharm Sci. 1999; 88: 955-8.

7. Barry BW. Breaching the skin's barrier to drugs. Nat Biotechnol. 2004; 22: 165-7.

8. Prausnitz MR, Mitragotri S, Langer R. Current status and future potential of transdermal drug delivery. Nat Rev Drug Discov. 2004; 3: 115-24.

9. Pilgram GS, Van Pelt AM, Spies F, Bouwstra JA, Koerten HK. Cryo-electron diffraction as a tool to study local variations in the lipid organization of human stratum corneum. J Microsc. 1998; 189: 71-8.

10. Sweeney TM, Downing DT. Role of lipids in the epidermal barrier to water diffusion. J Invest Dermatol. 1970; 55: 135-40.

11. Williams AC, Barry BW. Skin absorption enhancers. Crit Rev Ther Drug. 1992; 9: 305-53.
12. Mitragotri S. Immunization without needles. Nat Rev Immunol. 2005; 5: 905-16.

13. Williams AC, Barry BW. Penetration enhancers. Adv Drug Deliv Rev. 2004; 56: 603-18.

14. Hinz RS, Lorence CR, Hodson CD, Hansch C, Hall LL, Guy RH. Percutaneous penetration of parasubstituted phenols in vitro. Fund Appl Toxicol. 1991; 17: 575-83.

15. Hadgraft J. Dermal and transdermal drug design. Int J Pharm Med. 1999; 13: 155-8.

16. Pardo A, Shiri Y, Cohen S. Percutaneous absorption of physostigmine: optimization of delivery from a binary solvent by thermodynamic control. J Pharm Sci. 1990; 79: 573-8.

17. Thakur RA, Wang Y, Michniak BB. Essential oils and terpenes. Percutaneous Penetration Enhancers (2nd Edition). 2006: 159-73.

18. Okabe H, Obata Y, Takayama K, Nagai $T$. Percutaneous absorption enhancing effect and skin irritation of monocyclic monoterpenes. Drug Des Deliv. 1990; 6: 229-38.

19. Obata Y, Takayama K, Machida Y, Nagai T. Combined effect of cyclic monoterpenes and ethanol on percutaneous absorption of diclofenac sodium. Drug Des Discov. 1991; 8: 137-44.

20. Kang L, Poh AL, Fan SK, Ho PC, Chan YW, Chan SY. Reversible effects of permeation enhancers on human skin. Eur J Pharm Biopharm. 2007; 67: 14955.

21. Yamane MA, Williams AC, Barry BW. Effects of terpenes and oleic acid as skin penetration enhancers towards 5-fluorouracil as assessed with time; permeation, partitioning and differential scanning calorimetry. Int J Pharm. 1995; 116: 237-51.

22. Zhao L, Li Y, Fang L, Ren C, Xu Y, He Z. Effect of $\mathrm{O}$-acylmenthol and salt formation on the skin permeation of diclofenac acid. Drug Dev Ind Pharm. 2009; 35: 814-26.

23. Diez-Sales O, Garrigues TM, Herraez JV, Belda R, Martin-Villodre A, Herraez M. In vitro percutaneous penetration of acyclovir from solvent systems and carbopol 971-P hydrogels: Influence of propylene glycol. J Pharm Sci. 2005; 94: 1039-47.

24. Arellano A, Santoyo S, Martín C, Ygartua P. Influence of propylene glycol and isopropyl myristate on the in vitro percutaneous penetration of diclofenac sodium from carbopol gels. Eur J Pharm Sci. 1999; 7: 129-35.

25. Levang AK, Zhao K, Singh J. Effect of ethanol/propylene glycol on the in vitro percutaneous absorption of aspirin, biophysical changes and macroscopic barrier properties of the skin. Int $\mathrm{J}$ Pharm. 1999; 181: 255-63.

26. Borras-Blasco J, Lopez A, Morant MJ, Diez-Sales O, Herraez-Dominguez M. Influence of sodium lauryl sulfate on the in vitro percutaneous absorption of compounds with different lipophilicity. Eur J Pharm Sci. 1997; 5: 15-22.

27. Obata Y, Maruyama Y, Takayama K. The mode of promoting activity of O-ethylmenthol as a transdermal absorption enhancer. Pharm Res. 2006; 23: 392-400. 
28. Lombry C, Dujardin N, Preat V. Transdermal delivery of macromolecules using skin electroporation. Pharm Res. 2000; 17: 32-7.

29. Knutson K, Potts RO, Guzek DB, Golden GM, McKie JE, Lambert WJ, Higcuhi WI. Macro- and molecular physical-chemical considerations in understanding drug transport in the stratum corneum. J Control Release. 1985; 2: 67-87.

30. Panchagnula R, Desu H, Jain A, Khandavilli S. Feasibility studies of dermal delivery of paclitaxel with binary combinations of ethanol and isopropyl myristate: role of solubility, partitioning and lipid bilayer perturbation. Farmaco. 2005; 60: 894-9.

31. Hatta I, Ohta N, Inoue K, Yagi N. Coexistence of two domains in intercellular lipid matrix of stratum corneum. Biochim Biophys Acta Biomembr. 2006; 1758: 1830-6.

32. Ohta N, Ban S, Tanaka H, Nakata S, Hatta I. Swelling of intercellular lipid lamellar structure with short repeat distance in hairless mouse stratum corneum as studied by X-ray diffraction. Chem Phys Lipids. 2003; 123: 1-8.

33. Patel SR, Zhong H, Sharma A, Kalia YN. In vitro and in vivo evaluation of the transdermal iontophoretic delivery of sumatriptan succinate. Eur J Pharm Biopharm. 2007; 66: 296-301.

34. Chantasart D, Pongjanyakul T, Higuchi WI, Li SK. Effects of oxygen-containing terpenes as skin permeation enhancers on the lipoidal pathways of human epidermal membrane. J Pharm Sci. 2009; 98: 3617-32.

35. Yamane MA, Williams AC, Barry BW. Terpene penetration enhancers in propylene glycol/water cosolvent systems: effectiveness and mechanism of action. J Pharm Pharmacol. 1995; 47: 978-89.

36. Narishetty STK, Panchagnula R. Transdermal delivery of zidovudine: effect of terpenes and their mechanism of action. J Control Release. 2004; 95: 367-79.

37. Jain AK, Thomas NS, Panchagnula R. Transdermal drug delivery of imipramine hydrochloride. I. Effect of terpenes. J Control Release. 2002; 79:93-101.

38. Data from SciFinder ${ }^{\mathbb{B}}$ Scholar.

39. Nokhodchi A, Sharabiani K, Rashidi MR, Ghafourian T. The effect of terpene concentrations on the skin penetration of diclofenac sodium. Int $\mathrm{J}$ Pharm. 2007; 335: 97-105.

40. Zhao K, Singh J. Mechanism(s) of in vitro percutaneous absorption enhancement of tamoxifen by enhancers. J Pharm Sci. 2000; 89: 771-80

41. Clancy MJ, Corish J, Corrigan OI. A comparison of the effects of electrical current and penetration enhancers on the properties of human skin using spectroscopic (FTIR) and calorimetric (DSC) methods. Int J Pharm. 1994; 105: 47-56.

42. Bentley MV, Vianna RF, Wilson S, Collett JH. Characterization of the influence of some cyclodextrins on the stratum corneum from the hairless mouse. J Pharm Pharmacol. 1997; 9: $397-$ 402.

43. Moore DJ, Rerek ME, Mendelsohn R. Lipid domains and orthorhombic phases in model stratum corneum: evidence from Fourier transform infrared spectroscopy studies. Biochem Biophys Res Commun. 1997; 31: 797-801.

44. Csizmazia E, Eros G, Berkesi O, Berko S, SzaboRevesz P, Csanyi E. Ibuprofen penetration enhance by sucrose ester examined by ATR-FTIR in vivo. Pharm Dev Technol. 2012; 17: 125-8.

45. Boncheva M, Damien F, Normand V. Molecular organization of the lipid matrix in intact Stratum corneum using ATR-FTIR spectroscopy. Biochim Biophys Acta Biomembr. 2008; 1778: 1344-55.

46. Golden GM, Guzek DB, Kennedy AE, McKie JE, Potts RO. Stratum corneum lipid phase transitions and water barrier properties. Biochemistry. 1987; 26: 2382-8.

47. Dias M, Naik A, Guy RH, Hadgraft J, Lane ME. In vivo infrared spectroscopy studies of alkanol effects on human skin. Eur J Pharm Biopharm, 2008; 69: 1171-5.

48. White NS, Errington RJ. Fluorescence techniques for drug delivery research: theory and practice. Adv Drug Deliv Rev. 2004; 57: 17-42.

49. Alvarez-Roman R, Naik A, Kalia YN, Fessi H, Guy RH. Visualization of skin penetration using confocal laser scanning microscopy. Eur J Pharm Biopharm. 2004; 58: 301-16.

50. Fowler SD, Greenspan P. Application of Nile red, a fluorescent hydrophobic probe, for the detection of neutral lipid deposits in tissue sections: comparison with oil red O. J Histochem Cytochem. 1985; 33: 833-6.

51. Honig MG, Hume RI. Dil and diO: versatile fluorescent dyes for neuronal labelling and pathway tracing. Trends Neurosci. 1989; 12: 333-5.

52. Talreja P, Kleene NK, Pickens WL, Wang TF, Kasting GB. Visualization of the lipid barrier and measurement of lipid pathlength in human stratum corneum. AAPS Pharm Sci. 2001; 3: E13.

53. Furuishi T, Fukami T, Suzuki T, Takayama K, Tomono K. Synergistic effect of isopropyl myristate and glyceryl monocaprylate on the skin permeation of pentazocine. Biol Pharm Bull. 2010; 33: 294-300.

54. Bouwstra JA, Gooris GS, van der Spek JA, Bras W. Structural investigations of human stratum corneum by small-angle X-ray scattering. J Invest Dermatol. 1991; 97: 1005-12.

55. Madison KC, Swartzendruber DC, Wertz PW, Downing DT. Presence of intact intercellular lipid lamellae in the upper layers of the stratum corneum. J Invest Dermatol. 1987; 88: 714-8. 